Colleges are not advisable but I would encourage all members to communicate their concern, at both local and national levels, to as many people as possible.

J. L. T. BIRLEY President

\section{A unit for the 'intractably disturbed'}

DeAR Sirs

Oxford has for over 25 years been engaged in the active rehabilitation of the chronically mentally ill. For the last ten years we have increasingly concentrated on that group which is usually called the "new long stay'. We have avoided that term and developed services such as the Young Adult Unit (Pullen, 1987; 1988) which aim to prevent patients becoming long stay. In general the extensive network of specialist units, group homes and hostels has allowed us to prevent the build up again of large numbers of long stay patients. Nevertheless, in recent years it has become apparent that there are a few patients whom we feel it will never be possible to manage safely outside of a hospital setting.

This group includes men and women whose psychotic illness is so severe and so refractory that they would either be at risk to themselves in the community or would be a danger to the public. We exclude those who can be deemed a "grave and immediate threat to the public" because by definition such patients should be treated in a Special Hospital. It follows that our group needs to be contained but does not need the most sophisticated levels of security such as found in Secure Units.

It is difficult to predict how many such patients will be generated in the future, but our experience in Oxford suggests that for us it is at least one per million population per annum. We have, therefore, decided to open a unit specifically for this group of patients.

It is clear that such a unit must somehow balance the need to be a safe and containing environment with the necessity of providing a place which can be home for a patient, perhaps for $\mathbf{4 0}$ years. I would be grateful if anyone who is planning, or better still has built, such a unit, would get in touch with me in order to share information.

Young Adult Unit

G. P. Pullen

Littlemore Hospital

Littlemore, Oxford $O X 44 X N$

\section{Reference}

Pullen, G. P. (1987, 1988) The Oxford Service for the Young Adult Chronically Mentally Ill. Bulletin of the Royal College of Psychiatrists, 11, 377-379; 12, 64.

\section{Beware of your friendly social worker}

\section{DEAR SIRS}

Perhaps the most satisfactory way of resolving the disturbing problems raised by Dr Bridges (Psychiatric Bulletin, April 1989, 13, 197-198) is to involve patients more actively in decisions about confidentiality. Individuals using psychiatric services whether as in-patients or out-patients - are doing so to obtain medical assessment and treatment, and therefore the ethics of medical confidentiality apply. This is clearly recognised in DHSS guidelines.

Multidisciplinary working has developed without the express consent of patients. In addition there is no generally agreed style of multidisciplinary involvement, excepting perhaps between the medical and nursing professions and certain technical services. Where detailed discussion of sensitive and personal matters may occur - for example, in ward rounds, in the presence of professionals not directly working with the particular patient - our own ethical guidelines surely demand that the patient should know that this may happen and have a right to restrict discussion of their affairs, while under medical care, at least in accordance with the statements of the General Medical Council quoted by Dr Bridges.

Consultants may well have differing views on the extent to which restricted discussion will impair the ultimate treatment - based on their perceptions of multidisciplinary practice and the relative weights that they may attribute to perspectives unique to separate disciplines, improved information, or general experience that may be brought to ward meeting but in most cases it must surely be the patient's decision to determine, in consultation with the psychiatrist, how their treatment is conducted. In the same way 'joint' interviews should not be forced on patients unless there are particular reasons why the presence of a third party is desirable.

Finally would it be mischievous to speculate on whether the unit manager or social workers referred to by Dr Bridges would express similar views if in receipt of services for themselves or involved in administration in the private sector?

\section{Birch Hill Hospital}

D. M. BOWKER

\title{
Assessment of forensic cases on remand
}

DEAR SIRS

There is a serious problem in relationship to making psychiatric assessments of patients on remand in prison. I usually find that there is a complete absence of the depositions related to the offence for which the prisoner has been remanded. As a result, it is not always possible to make a satisfactory assessment 